\title{
PENGEMBANGAN PERANGKAT PEMBELAJARAN BERBASIS PROBLEM BASED LEARNING KELAS X MIA SMA
}

\author{
Mastang ${ }^{1}$ \\ Muhammad Rapi ${ }^{2}$ \\ ${ }^{1,2}$ Prodi Pendidikan Biologi Universitas Islam Negeri Alauddin Makassar \\ E-mail: ${ }^{1}$ mastang.asta06@g mail.com, ${ }^{2}$ mrapi@uin-alauddin.ac.id
}

\begin{abstract}
The aims of developing this learning tool are to provide learning tools that enable teachers to apply valid, effective and effective problem based learning by using the model developed by S. Thiagarajan et al. The 4-D development model consists of 4 main stages: Define, Design, Develop and Disseminate. Given the limitations of time, effort and cost, the learning device development model only goes to stage 3 of the 4-D model. Subjects in this study were students of class X MIA 1 SMA Muhammadiyah Limbung academic year 2017/2018. The data has been obtained and then analyzed using descriptive data analysis. Based on the analysis, the leaming tools developed are an invalid category with an average score of 3.29. The observation result of learning device implementation has an average of 3.44 in the medium category and implemented and the response of learners more than 80\% gives a positive response. While the assessment for students' learning outcomes shows the average value of Post-Test 81.7 and the N-Gain index 0.62 in the medium category. The results obtained can be concluded that the learning tools based on problem-based learning developed have met the category valid, practical and effective so it can be said feasible to use.
\end{abstract}

Kata kunci: Pengembangan, perangkat pembelajaran, problem based learning

Pemerintah menyempurnakan kurikulum, sebelumnya dinamakan kurikulum tingkat satuan pendidikan (KTSP) menjadi Kurikulum 2013. Penyempurnaan kurikulum juga mesti diikuti dengan adanya perubahan cara ataupun pola pandang individu, terutama oleh tenaga pendidik dalam menjalankan kurikulum tersebut (Rapi, 2016: 298).

Salah satu kompetensi yang mesti ditingkatkan kurikulum 2013 adalah keterempilan peserta didik dalam menyelesaikan suatu permasalahan, terutama yang berkaitan dengan permasalahan keseharian peserta didik. Keterampilan pemecahan masalah dapat dilatihkan bila didukung proses belajar mengajar yang mengarahkan peserta didik aktif mencari cara atau alternatif lain dari permasalahan yang telah diberikan.

Keberhasilan belajar peserta didik dapat diraih jika diawali dengan rancangan atau perencanaan pembelajaran yang baik (Rapi dan Ali, 2017: 203). Karena itu, diperlukan perangkat pembelajaran yang mendukung dalam melatihkan keterampilan pemecahan masalah.

Hasil penelitian pendahuluan di SMA Muhammadiyah Limbung, Kabupaten Gowa pada mata pelajaran Biologi terlihat bahwa alat-alat yang digunakannya sudah bervariasi. Namun bahan ajar yang digunakan belum dikembankan secara mandiri dan sebagian besar dari penerbit. Begitu pula dengan lembar kerja berpatokan pada soal-soal yang terdapat di dalam buku paket dan 
kurang sesuai dengan paradigm kurikulum 2013.

Di antara usaha yang dapat dilakukan mengatasi permasalahan tersebut adalah dengan membuat dan mengembangkan suatu perangkat pembelajaran yang sesuai dengan berdasarkan kurikulum 2013, yakni dengan mengaplikasikan suatu model yang terstruktur sesuai dengan langkah-langkah pembelajaran saintis dan model pembelajaran yang diimplementasikan diharapkan mampu membimbing kreativitas berpikir peserta didik secara merata. (Nurmaliati, 2015:47)

Problem Based Learning atau PBL merupakan salah satu model yang dapat dijadikan sebagai solusi dari permasahan tersebut. PBL merupakan suatu model pembelajaran yang mengarahkan peserta didik pada masalah sebagai rangsangan awal yang dapat mendorong peserta didik menggunakan pengetahuannya dalam menganalisa permasalahan, kemudian dilanjutkan dengan proses pencarian informasi yang bersifat student center melalui kegiatan diskusi dalam sebuah kelompok kecil (Volisa, 2014: 43). Salah satu materi pembelajaran yang memungkinkan peserta didik untuk dapat melihat masalah secara nyata dalam kehidupan sehari-hari adalah materi lingkungan yang memuat berbagai macam pencemaran lingkungan.

Berdasarkan kebutuhan tersebut, maka peneliti perlu melakukan adanya pengembangan perangkat pembelajaran. Perangkat pembelajaran dibatasi pada RPP, LKPD, media slide PowerPoint (PPT) dan Instrumen Penilaian Kognitif. Berdasarkan hal tersebut, terdapat 3 rumusan masalah pada penelitian ini yaitu, bagaimana tingkat kevalidan, kepraktisan serta keefektifan dari perangkat pembelajaran berbasis problem based learning pada peserta didik kelas $\mathrm{X}$ MIA 1 SMA Muhammadiyah Limbung Kabupaten Gowa.

Pembelajaran berbasis masalah atau Problem based learning (PBL) adalah pembelajaran yang penyampaiannya dilaksanakan dengan menyajikan suatu masalah, memberikan pertanyaan, memfasilitasi penyelidikan individu maupun kelompok serta membuka terjadinya dialog, dimana permasalahan yang disajikan hendaknya merupakan permasalahan yang bersifat kontekstual, sehingga mudah ditemukan oleh peserta didik dalam lingkungan sekitarnya (Sani, 2015: 140). Tujuan penggunaan metode ini yaitu untuk memberikan bekal kemampuan dasar dan teknik kepada peserta didik agar mampu memecahkan masalah yang sedang dihadapi, ketimbang hanya dicecoki dengan sejumlah data yang harus dihafalkan (Suyanto dan Jihad, 2013: 176).

Pencemar lingkungan berdasakan sifatnya, bahan pencemar atau polutan terbagi kedalam dua bagian utama, yaitu (1) Bahan pencemar yang dapat terurai (biodegradable). Bahan pencemar yang terdegradasi terbagi menjadi dua kategori, yaitu terurai secara cepat dan lambat dan (2) Bahan pencemar yang tidak dapat terurai (nonbiodegradable). Sedangkan menurut tempat terjadinya pencemaran, maka pencemaran lingkungan dapat dikelompokkan ke dalam 3 bagian, yaitu pencemaran udara, tanah dan air. (Pujiyanto, 2014: 278-288) 


\section{METODE}

Penelitian ini merupakan penelitian pengembangan. Produk yang dikembangkan serta diuji kelayakannya adalah rencana pelaksanaan pembelajaran (RPP), lembar kerja peserta didik (LKPD), media slide PowerPoint (PPT) dan instrumen penilaian kognitif berbasis problem based learning.
Penelitian ini menggunakan model pengembangan 4-D yang dikembangkan oleh S. Thiagarajan yang terdiri atas 4 tahap utama yaitu: Define, Design, Develop dan Disseminate. Mengingat keterbatasan waktu, tenaga dan biaya maka model pengembangan perangkat pembelajaran hanya sampai ke tahap 3 dari model 4-D sebagaimana pada gambar 1.

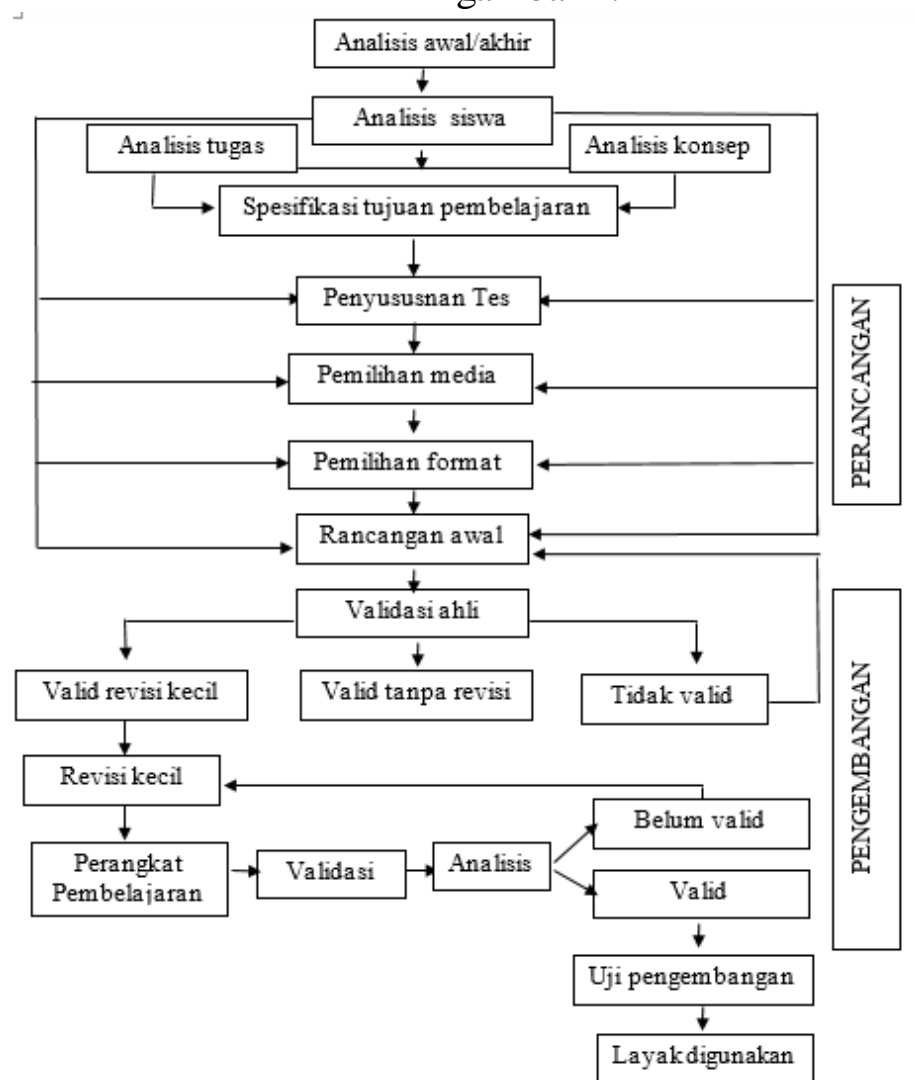

Gambar 1. Model Pengembangan Perangkat Hasil Modifikasi Peneliti

\section{Instrumen Penelitian}

Instrumen yang digunakan pada penelitian ini yaitu (1) Lembar validasi yang terbagi menjadi 2 yaitu lembar validasi instrumen dan instrumen validasi perangkat pembelajaran; (2) Angket terbagi menjadi 2 yaitu angket respon peserta didik dan lembar observasi keterlaksaan perangkat; dan (3) Butirbutir tes

\section{HASIL}

Tabel yang tertera di bawah ini merupakan tabel dari hasil pengolahan data hasil penelitian perangkat pembelajaran yang berbasis problem based learning yang telah melalui tahap validasi dan proses revisi berdasarkan saran dan masukan dari validator, begitu pula dengan instrument yang digunakan, hasil data tersebut dapat dilihat pada tabel 1 dan 2. Sedangkan tabel 3 merupakan data hasil keterlaksaan perangkat 
pembelajaran selama 2 kali pertemuan yang diisi oleh tiga obser (guru), sedangkan tabel 4 merupakan data hasil respon peserta didik. Dan hasil belajar pre-test dan post-test peserta didik dapat dilihat pada tabel 5 yang dilengkapi dengan hasil indek N-Gain.

\section{Data Kevalidan}

Tabel 1. Hasil Validasi Perangkat Pembelajaran

\begin{tabular}{clrc}
\hline No. & \multicolumn{1}{c}{ Perangkat } & $\overline{\boldsymbol{x}}$ & Keterangan \\
\hline 1 & $\begin{array}{c}\text { Rencana Pelaksanaan Pembelajaran } \\
\text { (RPP) }\end{array}$ & 3,24 & Valid \\
2 & Lembar Kerja Peserta Didik & 3,27 & Valid \\
& (LKPD) & 3,28 & Valid \\
3 & Slide PowerPoint (PPT) & 3,38 & Valid \\
\hline & Instrumen Penilaian Kognitif & $\mathbf{3 , 2 9}$ & Valid \\
\hline
\end{tabular}

Tabe12. Hasil Validasi Terhadap Instrumen Penelitian

\begin{tabular}{clcc}
\hline No. & Instrumen Penelitian & $\overline{\boldsymbol{x}}$ & Keterangan \\
\hline 1 & $\begin{array}{c}\text { Lembar observasi keterlaksanaan } \\
\text { perangkat pembelajaran }\end{array}$ & 3,38 & Valid \\
& $\quad$ Lembar angket respon peserta didik & 3,47 & Valid \\
2 & Tes hasil belajar & 3,38 & Valid \\
3 & $\quad$ Rata-rata & $\mathbf{3 , 4 1}$ & Valid \\
\hline
\end{tabular}

\section{Data Kepraktisan}

Tabel 3. Rekapitulasi hasil pengamatan keterlaksanaan perangkat

\begin{tabular}{cccc}
\hline \multirow{2}{*}{ No. } & Perte muan ke- & $\begin{array}{c}\text { Rata- } \\
\text { Rat } \\
\text { a }\end{array}$ & Keterangan \\
\hline 1 & Pembelajaran pertemuan pertama & 3,25 & Terlaksana \\
2 & Pembelajaran pertemuan kedua & 3,64 & Terlaksana \\
\hline & Rata-rata total & $\mathbf{3 , 4 4}$ & Terlaksana \\
\hline
\end{tabular}

Tabel 4. Rekapitulasi Hasil Respon Peserta Didik

\begin{tabular}{clccc}
\hline No. & Aspek & $\begin{array}{c}\text { Rata-Rata } \\
\text { Respon } \\
\text { Pernyataan } \\
\text { Positif }\end{array}$ & $\begin{array}{c}\text { Rata-Rata } \\
\text { Respon } \\
\text { Pernyataan } \\
\text { Negatif }\end{array}$ & Keterangan \\
\hline 1 & $\begin{array}{l}\text { Proses } \\
\text { pembelajaran }\end{array}$ & 3,47 & 1,67 & Sedang \\
2 & LKPD & 3,38 & 1,46 & Sedang \\
3 & PPT & 3,33 & 1,51 & Sedang \\
\hline \multicolumn{2}{c}{ Rata-Rata Total } & $\mathbf{3 , 3 9}$ & $\mathbf{1 , 5 4}$ & Sedang \\
\hline
\end{tabular}


Data Keefektifan

Tabe1 5. Data Pre-Test, Post-Test dan indeks Gain

\begin{tabular}{cc}
\hline Variabel & Nilai \\
\hline Subjek Penelitian & 35 \\
Rata-rata Post-Test (\%) & 81 \\
Rata-rata Pre-Test (\%) & 49,28 \\
Nilai Maksimal ideal & 100 \\
Nilai indeks N-Gain & 0,62 \\
Kategori Skor N-Gain & Sedang \\
\hline
\end{tabular}

\section{PEMBAHASAN}

Perangkat pembelajaran berbas is problem based learning ini diawali dengan tahap pendefinisian dalam bentuk analisis silabus Biologi SMA kelas $X$ semester 2 khususnya pada materi pencemaran lingkungan pokok bahasan macam-macam pencemaran lingkungan. Analisis yang dilakukan diantaranya adalah melakukan identifikasi kompetensi dasar (KD) 3.10. Selain analisis silabus, tahap ini pula dilakukan analisis ujung-depan, analisis peserta didik, analisis tugas, analisis konsep, dan perumusan tujuan pembelajaran. Tahap yang kedua adalah tahap perancangan sedangkan tahap yang ketiga adalah pengembangan. Tahap pengembangan diawali dengan proses validasi oleh para ahli sehingga menghasilkan prototipe ke II yang valid sehingga perangkat pembelajaran siap untuk dilakukan ujicoba.

Sebelum melakukan ujicoba di kelas yang menjadi subjek penelitian, maka terlebih dahulu peneliti melakukan tahap pra-uji coba. Tahap pra-uji coba melalui 2 tahap yaitu tahap ujicoba instrumen hasil belajar pada kepada peserta didik kelas diatasnya dari kelas yang menjadi subjek penelitian yaitu kelas XI IPA 1, XI IPA 2 dan kelas XI IPS 1 di SMA Muhammadiyah Limbung Kab. Gowa sehingga dapat diperoleh data berupa THB yang valid dan reliabel. Lalu tahap yang kedua dari tahap pra uji coba yaitu FGD (Forum Group Discussion), tahap ini merupakan pertemuan khusus peneliti dengan guru model yang akan menjadi pengajar dan guru yang akan menjadi observer.

Tahap selanjutnya yaitu tahap ujicoba dikelas sesungguhnya yaitu kelas X MIA 1 SMA Muhammadiyah Limbung, Kab. Gowa pada semester ganjil tahun pelajaran 2017/2018. Tahap ini diawali dengan pemberian soal pre-test yang terdiri dari 20 nomor soal pilihan ganda. Lalu melakukan proses belajar mengajar menggunakan perangkat yang telah dikembangkan selama 2 kali pertemuan, yang menjadi tenaga pengajar disini adalah guru Biologi dari kelas itu sendiri sedangkan guru yang menjadi observer adalah guru dari mata pelajaran lain yang mengisi lembar observasi keterlaksanaan perangkat pembelajaran. Setelah proses pembelajaran selesai maka langkah selanjutnya adalah pemberian soal post-test. Tahap terakhir yaitu pengisian angket respon peserta didik yang terdiri atas pernyataan positif dan pernyataan negatif.

\section{Data Kevalidan}

Hasil validasi terhadap perangkat pembelajaran menunjukkan bahwa keseluruhan rata-rata dari perangkat yang dikembangkan yaitu 
3,29 sedangkan hasil validasi terhadap instrumen penelitian mempunyai skor rata -rata 3,41 yang masing-masing berada pada kategori valid, yaitu $(2,5 \leq V<3,5)$. Penilaian secara umum oleh para ahli terhadap perangkat dan instrumen penelitian adalah baik serta dapat digunakan dengan sedikit revisi.

Setelah melalui tahap validasi maka perangkat pembelajaran yang telah dikembangkan dinyatakan dapat digunakan dalam proses pembelajaran. Menurut Nurfathurrahmah, perangkat pembelajaran dapat dinyatakan valid, jika penilaian para ahli menunjukkan bahwa pengembangan perangkat yang dibuat telah dilandasi oleh teori yang kuat serta memiliki konsistensi internal, yaitu terjadi saling keterkaitan antar komponen yang tertuang dalam perangkat yang dikembangkan. (Mustami dan Irwansyah, 2015:243)

Suatu perangkat pembelajaran dikatakan telah memiliki kriteria kevalidan jika perangkat tersebut telah memiliki kekonsistenan antar aspek dan bagian-bagian perangkat pembelajaran yang dibuat serta adanya kesesuaian antara tujuan, materi dan penilaian yang akan diberikan kepada peserta didik. (Rajabi dkk, 2015: 48-49)

\section{Data Kepraktisan}

Hasil analisis menunjukkan bahwa keterlaksanaan perangkat pembelajaran berada pada nilai ratarata $X=3,44$, sedangkan hasil analisis respon peserta didik menunjukkan bahwa rata-rata respon positif dari peserta didik sebesar 3,39 dan respon negatif dari peserta didik sebesar 1,54, yang berarti aspek dan kriteria yang dinilai pada keterlaksanaan perangkat dan angket respon peserta didik berada pada katergori sedang $(3 \leq \mathrm{Va}<4)$. Hal ini menunjukkan bahwa perangkat pembelajaran yang dikembangkan telah memenuhi kategori kepraktisan dan dapat dipergunakan dalam proses pembelajaran.

Berdasarkan data yang diperoleh dari pengamat, maka perangkat pembelajaran telah memenuhi kriteria kepraktisan pada kategori kepraktisan Trianto. Hal ini seseuai dengan penjelasan Dyah Purboningsi yang mengatakan bahwa suatu perangkat pembelajaran dapat dinyatakan kepraktisannya jika tenaga pendidik dan peserta didik telah mempertimbangkan keberadaan dari perangkat pembelajaran dengan anggapan bahwa perangkat tersebut mudah digunakan serta telah sesuai dengan rencana peneliti. (Purboningsih, 2015:469)

\section{Data Keefektifan}

Dari hasil analisis deskriptif diperoleh rata-rata nilai pre-test peserta didik sebesar 49,18. Setelah peserta didik melewati proses pembelajaran maka nilai rata-rata hasil belajar peserta didik telah mengalami peningkatan yang diperoleh dari hasil pemberian posttest sebesar 81,7. Terjadinya peningkatan dari hasil belajar peserta didik dapat pula dilihat dari nilai $N$ gain pre-test dan post-test peserta didik, setelah dilakukan analisis, diperolehnya nilai $N$-Gainnya sebesar 0,62 , yang berarti selisih peningkatan hasil belajar pre-test dan post-test peserta didik pada kelas X MIA 1 sebesar 0,62 yang berada pada kategori $(0,3<\mathrm{g} \leq 0,7)$ sedang, sedangkan hasil penilaian tugas penggunaan LKPD selama 2 kali pertemuan menunjukkan bahwa adanya peningkatan hasil pengerjaan 
tugas pada LKPD, pada pertemuan pertama 85,02 meningkat menjadi $89,08 \%$ pada pertemuan kedua.

Dari hasil pemberian post-test diperoleh data bahwa rata-rata nilai hasil belajar peserta didik secara keseluruhan, nilainya berada diatas KKM (yaitu berada di atas 70). Hal tersebut telah menunjukkan bahwa perangkat pembelajaran yang dikembangkan telah memenuhi kriteria keefektifan karena telah terjadi peningkatan hasil belajar peserta didik.

Suatu perangkat pembelajaran telah dapat dinyatakan keefektifannya apabila peserta didik telah berhasil selama mengikuti proses pembelajaran serta terdapat kekonsistenan antara pencapaian proses pembelajaran dan kurikulum. Dalam penelitian ini, perangkat pembelajaran yang dibuat dinyatakan efektif yang dibuktikan dengan tes hasil belajar peserta didik yang sudah sesuai dengan KKM. (Purboningsih, 2015:469)

\section{KESIMPULAN}

Berdasarkan nilai analisis data
tentang pengujian perangkat
pembelajaran berbasis problem based
learning yang terdiri atas RPP, LKPD, PPT serta instrumen penilaian kognitif maka disimpulkan (1) Perangkat pembelajaran memenuhi kategori valid dengan skor rata-rata 3,29 , kategori praktis dengan rata-rata hasil observasi pengamatan keterlaksanaaan perangkat 3,44 dengan kategori sedang sedangkan hasil angket respon peserta didik lebih dari $80 \%$ memberikan respon positif dan kategori efektif melihat rata-rata ketuntasan hasil belajar posttest peserta didik sebesar $81,7 \%$ dan nilai indeks $\mathrm{N}$-Gain antara pre-test dan post-test adalah 0,62 yang berarti peningkatan hasil belajar peserta didik berada pada kategori sedang.

\section{DAFTAR RUJUKAN}

Mustami, M. K. dan M. Irwansyah. 2015. Pengembangan Lembar Kerja Peserta Didik (LKPD) Berorientasi Pendekatan Saintifik Pada Mata Pelajaran Biologi SMA", Lentera Pendidikan 18 no. 2 (Desember 2015) : h. 243.

Nurmaliati, dkk. 2015. Pengembangan Perangkat pembelajaran Fisika SMA Materi Suhu dan Kalor Terintegrasi Thermoregulasi pada Manusia Berbas is Problem Based Learning". Edu-Sains 4, no. 2 (Juli 2015): h. 45-57. http://id.portalgaruda.org/?ref=b rowse \& mod=viewarticle \&articl $\mathrm{e}=420054$ (13 januari 2017).

Pujiyanto, S. 2014. Menjelajah Dunia Biologi 1 Untuk Kelas X SMA dan Ma Kelompok Peminatan Matematika dan Ilmu Alam. Jakarta: Platinum.

Purboningsih,

D. 2017.

Pengembangan Perangkat

Pembelajaran dengan

Pendekatan Guided Discovery pada Materi Barisan dan Deret Untuk Siswa SMK Kelas X". Seminar Nasional Matematika dan Pendidikan Matematika UNY 2015: h. 469 (10 Oktober 2017).

Rajabi, M., dkk. 2015. Pengembangan Perangkat Pembelajaran Instalasi Sistem Operasi dengan Model Pembelajaran Berbasis Proyek". Jurnal Pendidikan Vokasi : Teori dan Praktek 3, no. 1 (28 Februari 2015): h. 48-49. http://jurnalmahasiswa.unesa.ac .id/index.php/pendidikan- 
vokasi-teori-dan-

prak/article/view/13561 ( 10 oktober 2017).

Rapi dan Ali. 2017. Hubungan

Kemampuan Merancang

Perangkat Pembelajaran

Dengan Kinerja Praktik

Mengajar Mahasiswa Jurusan

Pendidikan Biologi". Lentera

Pendidikan 20, no. 2 (Desember

2017): h. 202-211.

http://journal.uin-

alauddin.ac.id/index.php/lentera -pendidikan/index (09 Januari 2018)

Rapi, M. 2016. Meningkatkan Aktivitas Dan Hasil Belajar Mata Kuliah Pengetahuan Lingkungan Hidup Melalui Pendekatan Scientific Mahasiswa". Jurnal Biotek 4, no. 2 (Desember 2016): h. 297 $314 . \quad$ http://journaluinalauddin.ac.id/index.php/biotek/ $\underline{\text { article/view/1886/1826 }} \quad(09$ Januari 2018)

Sani, R. A. 2013. Inovasi Pembelajaran. Cet. III; Jakarta: Bumi Aksara, 2015.

Suyanto dan A. Jihad. Bagaimana Menjadi Calon Guru Dan Guru Profesional. Cet. II; Yogyakarta: Multi Pressindo,

Volisa, M., dkk. 2014 .Pengembangan RPP Matematika dengan Problem Based Learning Berbasis Pendidikan Karakter pada Materi Dimensi Tiga". Edusainstika 1, no. 1 (Januari 2014): h. 43-45 http://id.portalgaruda.org/?ref=b rowse \& mod=viewarticle \&articl $\underline{\mathrm{e}=250829}$ 